\title{
The Development Strategy of Chinese Animation Industry in the Internet Plus Era
}

\author{
Hui Xie \\ Heihe University \\ Heihe, Heilongjiang, China
}

\author{
Guohua Gao \\ Heihe University \\ Heihe, Heilongjiang, China
}

\begin{abstract}
Animation industry has been recognized worldwide as one of the most potential development of the sunrise industries. With the rapid development of cultural diversity, cultural communication and influence of animation works cross regional, cross national, cross country possess the majority of the audience, attracting all countries because of its economic benefits. With the increasing prosperity of the cultural industry in recent years, China's animation industry has presented a good momentum of development, but facing industry development trends of Internet plus Animation and lacking of China's animation original talent, ability, technology and other aspects of the phenomenon, our animation industry should reshape the pattern of development, strengthen the talent pool, improve the industrial chain of all aspects to from a virtuous cycle for a new energy.
\end{abstract}

Keywords-China animation industry; development; strategy

\section{INTRODUCTION}

With the increasing prosperity of e culture industry, Chinese animation industry in recent years shows a good momentum of development. Chinese animation industry process however started late and still in the early development, industrial internal links development being not balanced. Facing increasing trend of the impact of the Internet+ on the development of the animation industry, we should seize the opportunity, actively learn from foreign countries in industrialization operation mode of animation industry and strengthen the application of animation talents training, so as to provide the talent guarantee for the rapid development of Chinese animation industry.

\section{DeVElopment Status of Chinese Animation INDUSTRY}

The history of the development of Chinese animation has been nearly a hundred years, since 1960s,1970s, Chinese animation gradually fade out of the international perspective. With the rapid development of the cultural life and the globalization of economic activities, the works of film and television art are of great interest to many countries, such as the artistic charm of its unique cultural communication and national style. With the rapid development of modern science and technology, the modern animation industry has become the most development potential of the sunrise industry. However, Chinese animation industry started late, comparing with the United States, Japan, South Korea and other countries, the quality of work is not high, the number is limited, the efficiency is low, and each link does not from a benign operation mechanism. China's animation works cannot meet the growing spiritual and cultural needs of people, and the animation industry in an immature state of the market.

\section{A. Animation Industry Has Not Yet Formed the Industrial Chain Operation Mode}

With the development of modern science and technology, the value of modern animation works expands from the pure art show to the economic value, national image display and promotion of national culture. Take the United States Disney Company as example, it has been one of the top 500 companies in America with its business model, leading the direction of the development of the world animation.

Chinese animation industry started since 2004, the state has introduced from the talent training to economic security, and then to restricting foreign cartoons broadcast time and other support policies, effectively promoting the rapid development of Chinese animation industry. Nearly 60cities in the country has established a base for the animation industry and thousands of animation companies came into being. However, Chinese animation has mainly relied on television broadcast media which is limited in space, coupling with the existing scale of small, scattered and weak in Chinese animation industry, although in recent years, the number of animation works increased, the product market acceptance is not high. There are few works which have bright themes, wide audience and the visual fancy effect. Animation companies have not formed a set of effective mode of operation in the animation works of art concepts, the content of the film form, the film market operation to the late derivative product development, etc, lacking of such leading companies like Disney, Hayao Miyazaki which is Japan's leading business, and the gap is huge compared with the United States, Japan, Korea these animation big countries.

\section{B. Chinese Animation Industry Has No Balanced Development for it Internal Link}

Animation industry is a knowledge-intensive and laborintensive industry, and the industry's talent ability, technology and personnel number has become the main reason for sustainable development of the industry. At present, from the release of the animation market effect, the general lack of Chinese animation companies such as writers, directors and 
marketing planning and other key talent, which leads to the phenomenon of younger age audience group, weak movie preplanning and deficient cartoon derivative product. Because of the low profitability, most of the animation business had to engage in foreign animation film of original animation manufacture to earn low cost, while huge markets potential of the animation derivative product market development is relatively weak, not forming a virtuous circle in industry downstream.

\section{The Development Trend of Internet+ Animation Industry}

Along with the in-depth application of video website and Internet, Internet communication platform is gradually replacing the traditional TV channel and paper-based publications and other media, and with the declination of traditional TV, paper-based publications and other media, animation industry becomes a kind of inevitable trend in expanding Internet media development. Traditional television, the film aired in the media, due to the broadcast time, schedule and other restrictions, has been unable to meet the aesthetic needs of the growing cultural needs of the audience enjoy the blossoms. Recently, with the popularity of online games, animation website, electronic books and other new media, the Internet animation entered the period of rapid development, providing unprecedented opportunities for development and raising new requirements for the operation mode of the Internet+.

\section{Imperfection of College Animation Talent Training Mechanism}

Animation industry is the combination of art and technology industry, and the dynamic integration of art painting, computer technology, film and TV art and other products. It requires corresponding talents should have high artistic quality, solid professional knowledge and other qualities, but some talent training of college animation major either pay more attention to software technology, or to the art. Students practice ability is weak, restricting the development of animation industry.

1) University personnel training does not meet the development of the animation industry environment: China's Animation talent training mode to a certain extent, affect and restrict the development of the industry. First of all, with the ability to create animation talent training teacher are insufficient, leading to art teachers who never engaged in the study of art become the main force of college animation personnel training. Secondly, in the pursuit of the maximization of the interests of institutions and the realistic situation of filling the animation market of "talent gap", it needs to combine college animation teachers in art teachers and computer teachers. Last, because of the lack of the actual needs of the community animation professionals market research, part of the colleges and universities is for imparting teaching, no in accordance with requirements of the market and the enterprise of application type talents training curriculum setting and carrying out corresponding practice link, resulting in the animation students lack of experience which colleges and universities raised, practice skills and innovative and creative ability, which is unable to meet the demand of the market and the enterprise.

2) The Construction of Hard Environment in Colleges and Universities: Although the animation industry is regarded as the 21st century's most promising sunrise industry, China's animation industry started later than other countries (such as Japan and South Korea, Europe and the United States started), which exists a certain gap in the hardware facilities. Some colleges and universities do not match advanced animation equipment available to students, even cannot meet the needs of teaching in the most basic technical platform. Students are not able to practice learning, only behind closed doors to be an armchair strategist, restricting learning animation industry development for talent training.

3) Practice Teaching Is not Deep Enough: Although some colleges and universities increase the practice base construction AND widely carry out school enterprise joint education and other measures, in order to provide students with practical ability and formulate the development of the corresponding measures. But due to the internal teaching physique, content, method, equipment is backward that cannot achieve reasonable docking with enterprises, which led to the animation teaching is not for the enterprise to provide substantial help, much less bringing benefits for the enterprise. Therefore, it led to a number of enterprises are unwilling to accept student intern, eventually all cultivation become empty talk.

\section{DEVELOPMENT STRATEGY OF CHINESE ANIMATION INDUSTRY}

\section{A. Actively Carry out the Comparison Research between Domestic and Foreign Animation Industry Operation Mode}

At present, Disney animation company in the United States, with its successful business model among the national top 500 enterprises in, American Internet gaming and animation industry is rapid development for the nation's largest entertainment industry, Japan and South Korea's animation industry also have been successful among national pillar industry of the national economy. Strengthening the national animation industry chain and business model research, drawing lessons from the operation mode of brand strategy and learning Japanese animation industry's close type in every link of the decision of labor make Chinese animation industry adapt the cartoons, network, games, comics and derivative products as an economy to break the traditional boundaries, commonly develop and go hand in hand with the strategy, so that China's animation industry coruscate exuberant vitality.

\section{B. Internet+Era Reshape the Animation Industry Chain}

With the implementation of state policy to support the cultural industry, animation industry in China also seizes the opportunity to accelerate development, and with on the Internet+ and new media platform increasingly influencing on the modern way of life of the people, Chinese animation 
industry enter to a new area whose integration and development cross shape, cross region, cross media, cross industry, and Internet + , related industries and the integration of the development of the industry will change the development pattern of the animation industry. Animation companies can transmit animation works which are made through the Internet platform, and animation works in the marketing channel gradually from the plane, TV media, news reading, outdoor ground campaign quickly to the Internet expand. It can develop animation enterprises, characters and brand marketing activities with Wechat, Weibo and other popular apps, using animation video network released the trailer for the animated cartoon, scenes, premiere and other promotional information.

\section{Comprehensive Promotion of Animation Talent Training Mechanism, Talent Support for the Promotion and Development of the Animation Industry}

1) Accurate Positioning of Talent Training Mode: Throughout the animation education system, the practice of teaching and education system plays a very important role. However, through the investigation of the general reflection of animation professional students' practical experience, professional application ability and technological innovation awareness is not very good integration. As the cradle of the animation talent training -- colleges and universities should actively carry out cooperation in running school with animation enterprises to train the animation professional skilled talents with strong practical ability for the enterprise, according to the animation industry of different production sectors of depth analysis and positioning of animation talent training standards to distinguish clear level of training system of talent and actively carry out cooperative education and related enterprises, setting up corresponding courses and specialized personnel training according to the actual needs of all sectors of the industry chain.

2) Integration of School and Animation Business Resources, Optimization of the training Model.

a) Integration of Enterprise and the Training of Teachers in Colleges and Universities: One of the key factors is the allocation of teachers, which affects animation professional talent training level. Due to the rapid development of animation industry in recent years, animation major also springs up in most Chinese universities. Some institutions or in the original art disciplines on the basis of the emphasis on teaching art set up relevant courses, or emphasizing technology training talent transformed from computer major, their teaching staff is constituted by diverted and transformed teachers of fine arts or computer major whose theory and practice have varying degrees of lack. Therefore, we should as soon as possible to construct a " teacher+ animation business creation teacher" teaching staff structure, building to enhance the double division type of teachers to promote team construction of animation major teachers to the strategic height of the sustainable development of the animation industry by developing cooperation of school and enterprises, sending excellent teachers training abroad, introducing overseas return " double teacher type" high-end animation talent, leading the project group and scientific research to improve level of teachers, and engaging high-end training institutions to start training, such as $\mathrm{Li}$ Wan International Art Education.

b) Adjustment of Talent Training Specifications according to the Requirements of Enterprises: According to the survey, we found that training animation professionals who can meet the practical needs of enterprises in the application animation must increase the practice of teaching aspects of setting. In talent training, we should progress and pay attention to both training structure of knowledge and ability of the cultivation of talents, timely carrying out the feedback research of animation industry market, making a accurate consideration of talent ability of animation industry and setting up targeted curriculum; On the running mechanism of school enterprise cooperation to establish and perfect animation enterprises and the animation talent training linkage mechanism, so that the level of school enterprise cooperation, the enrollment scale and School of professional animation, employment, teaching, training and other aspects of the organic fusion, forming multi-party participation and the benign cycle mechanism.

c) The Exploration on the Training Mode of Animation Professionals: Animation industry is an emerging strategic industries and different animation enterprises according to the product positioning in the production management, thematic conception, enterprise culture, artistic forms, technical means and work flow have different requirements, which makes the in Animation talent training mode for continuous innovation, through actively carry out school enterprise cooperation, under the leadership of professional teachers and the animation business part-time teachers, the learning of professional knowledge, master the practical skills, achieve and related enterprises to conduct joint training applied talents, to enable students to have some practical experience, so that the final purpose of theory and practice of refoulement times.

\section{REFERENCES}

[1] Analysis on the Problems and Countermeasures of the Cultivation of Cartoon Ralents in Higher Vocational Colleges, Yu Li, Wang Ru, China Electric Power Education, 2012,28 Journal.

[2] China Animation Industry Development Report (2014).

[3] China Animation Industry Development Report (2015).

[4] On the elements of national traditional culture in animation art, Jie Hui, Big Stage 2013.3. 